\title{
Prescription Coverage Options for Medicare Beneficiaries
}

\author{
Emily R. Cox and Cindy Jernigan
}

\begin{abstract}
OBJECTIVE: To describe how Medicare beneficiaries pay for prescription medications, discuss how various plan options differ in benefit design, and discuss issues of critical importance in regard to coverage for outpatient prescription medications under Medicare.
\end{abstract}

DATA SOURCES: Literature references.

CONCLUSION: Coverage for prescription medications is a highly desired benefit and a necessary one for certain low-income elderly. However, the provision of comprehensive pharmacy benefits under Medicare may be cost prohibitive in light of the necessary savings projections needed to protect the Medicare trust. How and if policymakers propose to provide prescription coverage under Medicare is yet to be seen.

KEYWORDS: Medicare, Medigap, Prescription coverage, Beneficiary, Medication

J Managed Care Pharm 1999: 250-54

\section{$\mathbf{A}$}

AUTHORS

EMILY R. COX, PH.D., is Assistant Professor, Department of Pharmacy Practice and Science, College of Pharmacy, University of Arizona, Tucson, AZ. CINDY JERNIGAN, R.PH., M.S., is Health Data Analyst, Kansas Foundation for MedicalCare, Topeka, KS.

Copyright 0 1999, Academy of Managed Care Pharmacy, Inc. All rights reserved.

CE CREDIT: This is article number 233-000-99-003-HO4 in AMCP's continuing education program. It affords 1 hour (.1 CEU) of credit.

Learning objectives and test questions follow on page 257.
$\mathrm{M}$ edicare was enacted in 1965 to provide health care coverage to Americans 65 years of age and older, $50 \%$ of whom had no form of health insurance at that time. ${ }^{1}$ In 1972, eligibility for Medicare was expanded to include the nonelderly disabled and persons with end-stage renal disease (ESRD). Since its inception, traditional fee-forservice (FFS) Medicare has not covered outpatient prescription medications. Medicare beneficiaries seeking protection from the financial risk of prescription costs are faced with limited options, some of which are financially prohibitive or unavailable. Here, we describe how Medicare beneficiaries pay for . prescription medications, discuss how the various plan options differ in terms of benefit design, and discuss issues of critical importance in regard to coverage for outpatient prescription medications under Medicare.

\section{MEDICARE}

Medicare is made up of two separate programs: Part A and Part B. Part A was designed to cover hospital expenses and is available to all Medicare beneficiaries. Workers and their dependents earn Part A eligibility through payment of payroll taxes during their working years. Part A coverage becomes available at age 65, or earlier if an individual qualifies for Social Security disability benefits or has ESRD. Medicare Part A covers inpatient hospital services, skilled nursing facility care following a hospitalization, home health care services, and hospice care for the terminally ill. For the first 60 days of a hospitalization, Medicare pays all reasonable expenses after the patient meets a deductible. For days 61-90, beneficiaries pay a daily coinsurance payment. In 1998, this coinsurance payment was $\$ 191$ per day, increasing to $\$ 382$ per day for days $91-150$, after which the Medicare beneficiary is responsible for all costs.

Medicare Part B is a voluntary program, providing supplemental medical insurance to Medicare beneficiaries willing to 
pay a monthly premium. Part B covers physician services and outpatient hospital services, including emergency room visits, outpatient surgery, laboratory services, diagnostic procedures, durable medical equipment, outpatient physical therapy, occupational therapy, and speech pathology services. Part B pays $80 \%$ of the approved amount for covered services after the beneficiary meets an annual deductible.

In 1967, 19.5 million individuals received health care coverage from the Medicare program. By 1996, enrollment had nearly doubled to 38.1 million. ${ }^{2}$ Although the number of nonelderly Medicare beneficiaries has grown steadily, those 65 years of age and older still make up approximately $87 \%$ of the Medicare population.

The growth in spending within the Medicare program has far outpaced enrollment growth. In 1967, the Medicare program provided $\$ 4.9$ billion in health care benefits; in 1996 , expenditures had increased to $\$ 203.1$ billion in benefits. ${ }^{3}$

Over the years, Medicare has consistently paid for about half of the average older American's medical expenses. ${ }^{4}$ There are.several mechanisms by which the elderly can supplement their Medicare coverage; many have purchased supplemental - plans or receive coverage through employer retiree health plans. These supplemental policies provide coverage for the high Medicare deductibles and copayments, as well as coverage for benefits not included within the basic benefit structure of traditional FFS Medicare, such as dental, vision, hearing, and prescription drugs. Table 1 presents the distribution of the Medicare population in 1996 by supplementary insurance status. Only $11.3 \%$ of Medicare beneficiaries had Medicare FFS as their sole form of health insurance, while $8 \%$ had sole coverage through managed care plans. ${ }^{5}$ The largest percentage of beneficiaries had coverage provided through employer retirement plans (29.9\%) while $28.4 \%$ of Medicare beneficiaries purchased additional supplemental coverage through one of 10 private Medigap policies. Approximately $17 \%$ of beneficiaries received coverage through state Medicaid programs. This included Medicare beneficiaries who met certain income requirements (Qualified Medicare Beneficiaries or Specified Low-Income Medicare Beneficiaries) or who were receiving Supplemental Security Income. Less than 5\% of Medicare beneficiaries had both employer and Medigap coverage.

One coverage option for Medicare beneficiaries that has received considerable attention recently is the HMO risk plan. In 1996, the number of beneficiaries enrolled in managed care grew by 80,000 each month. ${ }^{6}$ By January 1997 , more than 4.9 million individuals had enrolled in Medicare managed care plans, an increase of $108 \%$ since $1993 .{ }^{7}$ One incentive for beneficiaries to join managed care plans is the availability of added benefits not covered under FFS Medicare, including routine physical examinations, eye exams, and outpatient prescription drugs. ${ }^{8}$ In a survey of more than 12,000 Medicare managed care enrollees, respondents most often cited coverage for prescription drugs as their reason for selecting a health plan. ${ }^{9}$
Although managed care plans have been able to contract with the Health Care Financing Administration (HCFA) to provide Medicare coverage since the program's inception, few managed care organizations did so until after the passage of the Tax Equity and Fiscal Responsibility Act (TEFRA) in 1982. TEFRA made it easier and more attractive for health maintenance organizations (HMOs) to contract with HCFA, and introduced the first risk-based contracts between HCFA and managed care plans. ${ }^{2}$

The Medicare managed care market grew slowly initially, and many plans exited the market after a short period of time for two primary reasons: low capitated payments and adverse selection. ${ }^{10}$ Many regional HMOs may have accepted payment rates that were too low to cover treatment costs. The Medicare program bases payments to managed care plans on the adjusted average per capita cost (AAPCC) of beneficiaries in a given geographic area. Regional plans receiving a lower-than-average AAPCC rate were more likely than others to exit the market in 1988. Evidence also suggests that many plans left the market due to adverse selection. Plans with high percentages of categorically disabled beneficiaries were unlikely to renew contracts with Medicare in 1988, as were plans that had previously offered prescription drug coverage. It has been suggested that prescription drug benefits attracted a less healthy group of enrollees, resulting in excessive costs to the managed care plan. ${ }^{10}$

\section{COVERAGE FOR PRESCRIPTION MEDICATIONS}

Of the $\$ 36$ billion spent in 1991 on prescription drugs, older Americans accounted for $\$ 12.7$ billion- $\$ 14.3$ billion of that expenditure. ${ }^{11}$ Older Americans are estimated to use prescription medications at twice the national average and almost three times that of Americans under age 65. ${ }^{12}$ Studies have shown that $80 \%-90 \%$ of ambulatory individuals 65 years of age and older take at least one prescription medication. ${ }^{13-16}$

Table 1. Supplemental Health Insurance for Medicare Beneficiaries 65 Years of Age and Older, 1996

\begin{tabular}{l|c}
\hline Type of Coverage & $\%$ Distribution \\
\hline Employer-sponsored coverage & $29.9 \%$ \\
\hline Individual Medigap coverage & $28.4 \%$ \\
\hline Medicaid & $16.5 \%$ \\
\hline Medicare only for those in fee-for-service & $11.3 \%$ \\
\hline Medicare only for those in Medicare managed care & $8.0 \%$ \\
\hline Both employer-sponsored and Medigap coverage & $4.2 \%$ \\
\hline Other & $1.7 \%$ \\
\hline
\end{tabular}

Adapted from Eppig et al., 1997 
Medicare beneficiaries consume on average 18.5 prescriptions per person per year. ${ }^{17}$ Evidence of adverse selection is apparent, as those with drug coverage consume on average 20.3 prescriptions per person per year, compared to 15.3 for those with no drug coverage.

Estimates indicate that Medicare beneficiaries pay from $50 \%-67 \%$ of total prescription expenditures out of pocket, due to the lack of coverage for outpatient drugs and limits on existing prescription benefit designs. ${ }^{17.18}$ In fact, prescription drugs almost certainly represent one of the largest out-ofpocket medical expenses among older Americans, ${ }^{19}$ estimated to amount to $\$ 303-\$ 355$ per year. ${ }^{17,18}$

The inclusion of a prescription drug benefit is highly attractive among Medicare beneficiaries, due primarily to high out-of-pocket expense. In a recent survey of adults 65 years of age and older, $50 \%$ listed prescription drug coverage as one of the first three choices of health care coverage they would prefer to receive. ${ }^{20}$ The only types of coverage cited more often were hospitalization and outpatient care.

Coverage for outpatient prescription drugs varies greatly among the various plan types listed in Table 1. Data from the 1995 Medicare Current Beneficiary Survey (MCBS) provide the most up-to-date profile of prescription coverage and utilization among Medicare beneficiaries. ${ }^{17}$ Table 2 presents the percentage of Medicare beneficiaries with drug coverage by type of coverage. These findings suggest that approximately. $65 \%$ of Medicare beneficiaries have some type of coverage for prescription medications. This is higher than previous estimates indicating that $50 \%$ of Medicare beneficiaries had some type of prescription coverage. ${ }^{21}$ The MCBS survey separated coverage for prescriptions based on whether coverage was provided by the respondent's primary source of insurance or from secondary sources.

\section{Prescription Coverage Under Fee-For-Service Medicare}

Traditional FFS Medicare does not include an outpatient drug benefit. However, under certain circumstances, Medicare Part $B$ covers drugs that are used with durable medical equipment or infusion equipment, as well as drugs used in association with dialysis or organ transplantation, chemotherapy, cancer pain management treatment, and certain types of vaccines such as those for flu and hepatitis B. Payments for prescriptions under Part B have increased $25 \%$, from $\$ 1.8$ billion in 1995 to $\$ 2.3$ billion in 1996 - a substantial sum by anyone's estimation. ${ }^{22}$

\section{Prescription Coverage Under Employer-Sponsored Plans}

According to 1995 MCBS data, approximately $84 \%$ of Medicare beneficiaries who received health coverage through their employer also received coverage for prescription drugs. Those eligible to receive benefits include those 65 years of age and older who are still employed and retired workers and their dependents. ${ }^{23}$ The way in which benefits are provided varies by employer group but often is comprehensive. The trend among employer-sponsored health plans is to encourage retirees to select managed care plans.

\section{Prescription Coverage Under Medicare Risk}

Approximately $95 \%$ of Medicare beneficiaries enrolled in managed care have some form of prescription coverage. Estimates of the percentage of Medicare managed care plans that offer prescription drug coverage range from just over $60 \%$ to $78 \% .{ }^{24}$ Meyer and colleagues ${ }^{25}$ found that of the plans offering a comprehensive drug benefit, $87 \%$ limited the benefit to a maximum benefit per time period, ranging from a low of $\$ 500$ annually to a high of $\$ 4,000$. Management of prescription benefits included patient cost sharing (copays range from \$3-\$30), mail-order services, formularies, prior authorization, generic substitution, physician education, and drug utilization review. The extent to which each was implemented varied widely among plans.

The generosity of the pharmacy cap and patient cost sharing often depends upon AAPCC rates and market competition with benefits for those beneficiaries living in rural areas, often less generous than their urban counterparts, requiring higher copayments and lower annual capped amounts.

Although enrollment in managed care plans had been growing at a brisk pace, in the fall of 1998 HMOs in 29 states announced that they were opting out of Medicare risk altogether or cutting back on benefits, ${ }^{26}$ moves estimated to affect more than 400,000 beneficiaries. Among the most important benefits being eliminated or reduced was coverage for prescription drugs. The HMOs took these actions in response to decreased profits in the Medicare managed care market and anticipated AAPCC payment changes stipulated under the Balanced Budget Act (BBA) of 1997, ${ }^{27}$ which ensured a minimum payment of $\$ 367$ per member per month to Medicare

Table 2. Distribution of Noninstitutional Medicare Beneficiaries by Type of Supplemental Insurance and Presence of Drug Coverage, 1995

\begin{tabular}{l|c|c|c}
\hline Type of Coverage & $\begin{array}{c}\text { With primary } \\
\text { drug coverage }\end{array}$ & $\begin{array}{c}\text { With secondary } \\
\text { drug coverage }\end{array}$ & $\begin{array}{c}\text { No drug } \\
\text { coverage }\end{array}$ \\
\hline All persons & $61.7 \%$ & $3.4 \%$ & $34.8 \%$ \\
\hline Medicare risk HMO & $95.0 \%$ & $\cdot$ & $4.1 \%$ \\
\hline Medicaid & $87.8 \%$ & $2.0 \%$ & $10.2 \%$ \\
\hline Employer sponsored & $83.9 \%$ & $2.4 \%$ & $13.7 \%$ \\
\hline Individually purchased only & $28.9 \%$ & $7.0 \%$ & $64.1 \%$ \\
\hline All others & $78.5 \%$ & & $20.1 \%$ \\
\hline
\end{tabular}

Number is unreliable because of small sample size.

Adapted from Davis et al., 1999 
HMOs in 1998, and a minimum increase in payments of $2 \%$ over 1997. ${ }^{28}$ These measures created a payment floor designed to increase payments in areas such as rural counties that historically had low benefit payments. However, the methodology used to calculate AAPCC was altered to more accurately reflect health plan costs, thus lowering expected payment increases for many health plans. This change in methodology resulted from research that suggested HCFA expenditures for $\mathrm{HMO}$ enrollees was, on average, higher than expenditures would have been if the same beneficiaries had received care through traditional FFS Medicare. ${ }^{2}$ However, even with these changes in the Medicare managed care market, $68 \%$ of health plans providing Medicare coverage still provided some form of prescription drug benefit in $1998 .^{2}$

\section{Prescription Coverage Under Medigap Policies}

Medicare beneficiaries can purchase private insurance policies, also known as Medigap policies, that provide coverage for Medicare deductibles and coinsurance requirements. Ten Medigap policies, denoted by the letters A through J, are available to Medicare beneficiaries; however, only three of the 10 policies- $\mathrm{H}, \mathrm{I}$, and $\mathrm{J}$-contain a prescription benefit. Prescription coverage under these plans is limited, and enrollees are subject to high copayments and deductibles. Under plans $\mathrm{H}$, I, and J, beneficiaries must pay a $\$ 250$ deductible and $50 \%$ copayments, and benefits are capped at an annual limit of $\$ 1,250$ (plans $\mathrm{H}$ and I) or $\$ 3,000$ (plan J). According to the 1997 National Association of Insurance Commissioners' Medicare Supplement Data, only 13\% of beneficiaries with Medigap policies have opted into plans $\mathrm{H}$, I, or $\mathrm{J}$, due in part to the large premiums and high patient costsharing requirements. This would suggest that $13 \%$ of beneficiaries with private Medigap policies have prescription coverage, an estimate less than half of that provided by Davis and colleagues, ${ }^{17}$ who indicate that $29 \%$ of those with private Medigap insurance have prescription coverage. Some of these differences in estimates may be due to shifts from Medigap insurance to managed care during 1995 to 1997 , and differences in the methods of estimation.

\section{Prescription Coverage Under Medicaid}

Approximately $88 \%$ of Medicare beneficiaries who are dual-eligible for Medicaid have coverage for prescription medications. Patient cost sharing for prescription medications typically is not required; if copayments are required, they are usually nominal, ranging from $\$ 0.50-\$ 3 . .^{29}$ Prescription coverage is comprehensive, often including certain over-thecounter categories. The type of benefit design differs by state, with most imposing some quantity limits on either days supply or maximum number of prescriptions per month. In 1996, almost all states had in place formulary systems; more than half of those were open formularies. States use other management strategies as well, including prior approval, drug utilization review, and generic substitution.
In addition to coverage under Medicaid, some low-income elderly may be eligible for prescription coverage under some state plans. In 1996, 10 states implemented programs to provide drug benefit coverage for low-income elderly and disabled individuals whose income did not qualify them for Medicaid. Each program varies widely in terms of eligibility income requirements and program design. ${ }^{2}$

\section{POLICY ISSUES: PRESCRIPTION DRUG COVERAGE AND THE ELDERLY}

Older individuals are particularly dependent upon prescription medications, given the higher probability of chronic disease within this age group. Estimates suggest that $61.7 \%$ of those age $65-74$ have at least one chronic condition, ${ }^{30} \mathrm{com}$ pared to $21.4 \%$ of enrollees $18-24$ years of age.

Many medications used by older patients are considered essential to their health. ${ }^{31}$ Based on data from the 1990 National Disease and Therapeutic Index, the most commonly prescribed drugs among patients age 65 and older are cardiovascular agents, including digitalis, beta blockers, calcium channel blockers, and antiarrhythmics. In addition, diuretics and hypotensives, both used to treat cardiovascular conditions, are commonly prescribed to patients in this age group. ${ }^{15}$

The lack of coverage for prescription medications under Medicare has been called one of the most conspicuous deficiencies in the Medicare benefit. ${ }^{32}$ Although estimates indicate that $50 \%-65 \%$ of beneficiaries have coverage for prescription medications, many plans limit coverage through high copayments and deductibles or cap benefits at an annual dollar amount. These limits serve to place $50 \%-67 \%$ of the total financial burden for prescription medications on Medicare beneficiaries.

Out-of-pocket prescription drug costs represent a considerable burden on older Americans. ${ }^{18}$ On average, the elderly spend $3.1 \%$ of family income on out-of-pocket drug expenses. Those with some type of drug coverage spend $1.4 \%$, compared to $4.3 \%$ for those without coverage.

The financial burden of prescription costs is even greater among elderly who are low-income, and rural residents. ${ }^{18}$ Those categorized as poor, near poor, and low income spent an average of $5.8 \%, 5.4 \%$, and $5.9 \%$ of their family income, respectively, on out-of-pocket prescription drug expenditures, compared to only $1.6 \%$ of family income spent by middleincome respondents and $0.6 \%$ spent by high-income respondents. Rogowski and colleagues ${ }^{18}$ found that the financial burdens for prescription medications borne by elderly women were $20 \%$ higher than those of elderly men, due in part to the fact that many women were living alone and had low incomes.

Several factors make the economic reality even bleaker for low-income elderly. While the average annual growth rates in prescription expenditures have been in the double digits for the past several years, ${ }^{33}$ annual increases in Social Security income payments have been at their lowest rate in years (1.3\% effective January 1, 1999). 
Elderly persons living in rural areas spend $3.8 \%$ of family income on prescription medications, compared to $2.8 \%$ for elderly persons living in urban areas. Older Americans living in rural areas may find coverage for prescription medications even more difficult to obtain due to recent actions by HMO risk plans to discontinue coverage or reduce benefits, including prescription benefits, in many rural areas.

As part of the 1997 BBA, the National Bipartisan Commission on the Future of Medicare was established to ensure the solvency of the Medicare Part A trust fund. Prescription drug coverage has been included in the Commission's discussions. President Clinton also is proposing inclusion of coverage for prescription drugs under a plan to expand Medicare. ${ }^{34}$ There is no question that coverage for prescription medications is a highly desired benefit, and a necessary one for certain lowincome elderly. However, the provision of comprehensive pharmacy benefits under Medicare may be cost prohibitive in light of the savings projections needed to protect the Medicare trust. How and if policymakers propose to provide prescription coverage under Medicare is yet to be seen.

\section{References}

1. Vladeck BC, King KM. Medicare at 30: preparing for the future. JAMA 1995; 274(3): 259-62.

2. U.S. Health Care Financing Administration. The profile of Medicare chart book 1998. Washington, DC: HCFA; 1998.

3. U.S. Health Care Financing Administration. Highlights: national health care expenditures, 1996. Washington, DC: HCFA; 1998.

4. Etheredge L. Three streams, one river: a coordinated approach to financing retirement. Health Affairs 1999; 18(1): 80-91.

5. Eppig FJ, Chulis GS. Trends in Medicare supplementary insurance: 199296. Health Care Financing Review 1997; 19(1): 201-06

6. U.S. Health Care Financing Administration. HCFA statistics: highlights. Washington, DC: HCFA; 1996.

7. U.S. Health Care Financing Administration. 1997 guide to health insurance for people with Medicare standard Medigap plans. Washington, DC: HCFA; 1997

8. Oberlander JB. Managed care and Medicare reform. Health Politics, Policy and Law 1997; 22(2): 595-631

9. Wilson J. Medicare managed care: consumers' perspectives. Clinical Therapeutics 1998; 20(6): 1263-76.

10. Porell FW, Tompkins CP. Medicare risk contracting: identifying factors associated with market exit. Inquiry 1993; 30: 157-69.

11. Long SH. Prescription drugs and the elderly: issues and options. Health Affairs 1994; Spring:157-74.

12. Baum C, Kennedy DL, Knapp DE, et al. Prescription drug use in 1984 and changes over time. Medical Care 1986; 26: 105-14.

13. Darnell JC, Murray MD, Martz BL, et al. Medication use by ambulatory elderly: an in-home survey. J Am Geriatrics Society 1986; 34: 1-4.

14. Letsch SW. National health care spending in 1991. Health Affairs 1993; Spring: 94-110.

15. Stockton P, Jones JK. Medication use by the elderly. Aging and Clinical Experience Research 1993; 5: 337-347.

16. Michocki RJ, Lamy PP, Hooper FJ, et al. Drug prescribing for the elderly. Archives of Family Medicine 1993; 2: 44i-44.

17. Davis M, Poisal J, Chulis $G$, et al. Prescription drug coverage, utilization, and spending among Medicare beneficiaries. Health Affairs 1999; 18(1): 231 43.

18. Rogowski J, Lillard LA, Kington R. The financial burden of prescription drug use among elderly persons. The Gerontologist 1997; 37(4): 475-82. 19. Monane M, Bohn RL, Gurwitz JH, et al. Compliance with antihypertensive therapy among elderly Medicaid enrollees. Am J Public Health 1996; 86(12): 1805-08.

20. Danis M, Biddle AK, Henderson G, et al. Older Medicare enrollees' choices for insured services. J Am Geriatrics Society 1997; 45: 688-94.

21. Chulis GS, Eppig FP, Poisal J. Ownership and average premiums for Medicare supplementary insurance policies. Health Care Financing Review 1995; Fall: 255-74.

22. Office of Inspector General. Excessive Medicare payments for prescription drugs. U.S. Department of Health and Human Services, 1997 (OEI-03-9700290):

23. Perryman-Starkey M, Rivers PA, Munchus G. Retiree health benefits revisited. Health Care Management Review 1998; 23(1): 29-36.

24. Lamphere JA, Neuman P, Langwell $\mathrm{K}$, et al. The surge in Medicare managed care: an update. Health Affairs 1997; 16(3): 127-33.

25. Meyer JA, Bagby N, Tilton JM. HMO pharmacy benefits under Medicare risk contracts. Washington, DC: New Directions for Policy; 1997.

26. Pear R. As HMOs drop Medicare, many are left in quandary. New York Times Oct 18, 1998.

27. Burton TM, Lagnado L, McGinle L. As HMOs scramble to cut Medicare, patients face bumpy and costly ride. Wall Street Journal Interactive Edition 1998; Aug 11.

28. U.S. Health Care Financing Administration. Payments to Medicare + Choice organizations. 1998c. http//www.hcfa.gov.

29. National Pharmaceutical Council. Pharmaceutical benefits under state medical assistance programs. Reston, VA: National Pharmaceutical Council. 1996.

30. Fishman $P$, VonKorff $M$, Lozano $P$, et al. Chronic care costs in managed care. Health Affairs 1997; 16(3): 239-47

31. Shimp LA, Ascione PJ, Glazer HM, et al. Potential medication-related problems in noninstitutionalized elderly. Drug Intelligence and Clinical Pharmacy 1985; 19: 766-72.

32. Cassel CK, Besdine RW, Siegel LC. Restructuring Medicare for the next century: what will beneficiaries really need? Health Affairs 1999; 18(1): 118 33. Levit K, Cowan C, Braden B, et al. National health expenditures in 1997 more slow growth. Health Affairs 1998; 17(6): 99-110.

34. Pear R. Clinton's plan to have Medicare cover drugs means a big debate ahead in Congress. New York Times Jan 24, 1999. 
Upon completion of this article, the successful participant should be able to:

1. Describe the type and extent of medical coverage offered by Medicare Part A and Part B.

2. Identify sources of supplemental health insurance for Medicare beneficiaries.

3. Describe prescription use in the elderly and the financial burden it can place on this population.

4. Discuss the various sources of prescription drug coverage for the elderly. 5. Explain how the Balanced Budget Act of 1997 has affected prescription drug for the elderly.

\section{SELF-ASSESSMENT QUESTIONS}

1. Those eligible for Medicare do not include:
a. patients with end-stage renal disease.
b. the low-income nonelderly.
c. those 65 year of age or older.
d. the nonelderly disabled.

2. According to the article, the most common type of supplemental insurance for Medicare beneficiaries age 64 and older is:
a. individual Medigap policies.
b. employer-sponsored plans.
c. Medicaid.
d. Medicare managed care.

3. Added benefits of HMO risk plans (i.e., features not covered by traditional fee-for-service) Medicare do not include:

a. eye exams.

b. outpatient prescriptions. c. routine physical exams.

d. all of the above are included as an added benefit.

4. The percent of total prescription expenditures that are paid out-of-pocket by Medicaid beneficiaries is approximately:
a. $10 \%$
b. $20 \%$
c. $50 \%$
d. $90 \%$

5. Which of the following statements is true?

a. Less than $50 \%$ of Medicare enrollees have prescription drug coverage.

b. The percentage of elderly with prescription drug coverage varies by type of supplemental coverage.

c. Medicare enrollees in HMO risk plans are less likely to have prescription drug coverage than Medicare enrollees who are not in HMO risk plans.

d. None of the above statements are true.

6. Among HMO risk plans that offer prescription drug coverage for their Medicare enrollees, tools commonly used to manage the benefit do not include:
a. copayments.
b. stop-loss limits.
c. caps.
d. mail order .

7. Which of the following statements is not true?

a. In the fall of 1998, many Medicare risk plans announced they were reducing benefits or leaving the Medicare market altogether. b. One reason for the exit of Medicare risk plans was anticipated changes in the AAPCC payment rate.

c. Prescription drug benefits were not identified as one of the benefits to be removed.

d. All of the above statements are true.

8. Prescription drug coverage under Medigap policies:

a. is more generous (i.e., lower copayments and higher caps) than prescription coverage under Medicare risk plans.

b. is offered for 9 of the 10 available policies

c. is less common than prescription drug coverage under HMO risk plans.

d. has never been offered.

9. The most commonly prescribed drug class among patients 65 years of age and older is:

a. antidiabetic agents.

b. analgesics.

c. cough/cold products.

d. cardiovascular agents

10. Which of the following is not true?

a. The elderly spend an average of $3.1 \%$ of their income on prescription drugs.

b. The financial burden of prescription drugs is greater among low-income, elderly females.

c. The financial burden of prescription drugs in greater among elderly living in urban areas.

d. Small increases in Social Security income have contributed to the increased burden of prescription drug costs among the elderly 


\section{DEMOGRAPHIC INFORMATION (not for scoring)}

11. In what type of setting do you work (leave blank if none of the responses below applies)?
a. $\mathrm{HMO}$
b. PPO.
c. Indemnity insurance.
d. Pharmacy benefits management.
e. Other.

12. Did this program achieve its educational objectives?
a. Yes.
b. No.

13. How many minutes did it take you to complete this program, including the quiz (fill in on answer sheet)?

14. Did this program provide insights relevant or practical for you or your work?

a. Yes.

b. No.

15. Please rate the quality of this $\mathrm{CE}$ article.
a. Excellent.
b. Good.
c. Fair.
d. Poor.

\section{INSTRUCTIONS}

This quiz affords 1 hour (. 1 CEU) of continuing pharmaceutical education in all states that recognize the American Council on Pharmaceutical Education. To receive credit, you must score at least $70 \%$ of your quiz answers correctly. To record an answer, darken the appropriate block below. Mail your completed answer sheet to: Academy of Managed Care Pharmacy, $100 \mathrm{~N}$. Pitt Street, Suite 400, Alexandria, VA 22314. Assuming a score of $70 \%$ or more, a certificate of achievement will be mailed to you within 30 days. If you fail to achieve $70 \%$ on your first try, you will be allowed only one retake. The ACPE Provider Number for this lesson is 233-000-99-003-HO4. This offer of continuing education credits expires June 30, 2000.
A $B$ C $C$
$1.0 \square \square \square$
2. $\square \square \square$
3. $\square \square$
4. $\square \square \square$
5. $\square \square \square$
A $B$ C D
6. $\square \square \square$
7. $\square \square$
8. $\square \square$
9. $\square \square \square$
10. $\square \square \square$

11. $\square \mathrm{A} \square \mathrm{B} \square \mathrm{C} \square \mathrm{D}$

12. $\square$ Yes $\square$ No

13. Minutes

14. $\square$ Yes $\square$ No

15. $\square \mathrm{A} \quad \square \mathrm{B} \quad \square \mathrm{C} \quad \mathrm{D}$
Participant Identification: Please type or print

Date

Social Security \# For Identification Purposes Only

Name

$$
\text { Last }
$$

First

Middle
Work Phone \#

Company

Address

Street (with Apt. No.) or P.O. Box

City

State

Zip

State and Lic. No.

State

No.

Member Type: $\square$ Active $\square$ Supporting Associate

$\square$ Student $\square$ Nonmember

Signature 